\title{
Recognition of repulsive and attractive regions of selected serotonin receptor binding site using FMO-EDA approach
}

\author{
Paweł Śliwa $^{1}$ (D) $\cdot$ Rafał Kurczab $^{2} \cdot$ Rafał Kafel $^{2} \cdot$ Anna Drabczyk $^{1} \cdot$ Jolanta Jaśkowska $^{1}$
}

Received: 30 November 2018 / Accepted: 14 March 2019 / Published online: 6 April 2019

(C) The Author(s) 2019

\begin{abstract}
The complexes of selected long-chain arylpiperazines with homology models of 5- $\mathrm{HT}_{1 \mathrm{~A}}, 5-\mathrm{HT}_{2 \mathrm{~A}}$, and 5- $\mathrm{HT}_{7}$ receptors were investigated using quantum mechanical methods. The molecular geometries of the ligand-receptor complexes were firstly optimized with the Our own N-layered Integrated molecular Orbital and molecular Mechanics (ONIOM) method. Next, the fragment molecular orbitals method with an energy decomposition analysis scheme (FMO-EDA) was employed to estimate the interaction energies in binding sites. The results clearly showed that orthosteric binding sites of studied serotonin receptors have both attractive and repulsive regions. In the case of 5- $\mathrm{HT}_{1 \mathrm{~A}}$ and 5- $\mathrm{HT}_{2 \mathrm{~A}}$ two repulsive areas, located in the lower part of the binding pocket, and one large area of attraction engaging many residues at the top of all helices were identified. Additionally, for the $5-\mathrm{HT}_{7}$ receptor, the third area of destabilization located at the extracellular end of the helix 6 was found.
\end{abstract}

Keywords ONIOM $\cdot$ FMO-EDA $\cdot$ GPCR $\cdot$ Long-chain arylpierazines

\section{Introduction}

The application of quantum chemical methods for biological systems is usually computationally expensive. The fragment molecular orbital method (FMO) [1-3] is a convenient tool for calculating the energy of large systems at the ab initio level. The results give additional data that are troublesome to obtain with simple molecular mechanical methods. Originally, the FMO method simplified the total energy of a molecule or a molecular cluster divided into $\mathrm{N}$ fragments as the following sum:

$E=\sum_{I>J} E_{I J}-(N-2) \sum_{I} E_{I}$

where $E_{I}, E_{I J}$ are the energies of the monomer and dimer, respectively. For the receptor-ligand complexes, each residue

This paper belongs to Topical Collection 8th conference on Modeling \& Design of Molecular Materials (MDMM 2018)

Paweł Śliwa

psliwa@chemia.pk.edu.pl

1 Faculty of Chemical Engineering and Technology, Cracow University of Technology, 24 Warszawska, 31-155 Kraków, Poland

2 Department of Medicinal Chemistry, Institute of Pharmacology, Polish Academy of Sciences, 12 Sm tna, 31-343 Kraków, Poland which participates in ligand binding could by represented by fragment, whereas ligands can be represented by a single or multiple fragment as necessary. The result is the matrix of individual pair interaction energies (PIE) between all fragments. Additionally, the applied pair interaction energy decomposition analysis method (PIEDA or FMO-EDA) [2] supplies the electrostatic, exchange, charge transfer, and dispersion contributions to the total interaction energies, which is particularly useful for studying protein-ligand complexes. Currently, FMO allows also to estimate the solvation contribution by interfacing with the polarizable continuum model (PCM) method [4]. The FMO methodology was successfully applied to various large biological systems, primarily in a retrospective analysis of binding sites [5-16], but also as a tool supporting drug design [17-20]. Among these, several studies $[7,11,16,18]$ have focused on one of the most important groups of biological targets, a $\mathrm{G}$ protein-coupled receptors (GPCRs) family. The authors found crucial interactions that were often ignored by structure-based descriptions and indicated that the FMO scheme would be a valuable tool for structure-based drug design by estimations of the chemical character of the proteins binding site.

In this work, quantum chemical methods were used for the energy characterization of binding sites of $5-\mathrm{HT}_{1 \mathrm{~A}}, 5-\mathrm{HT}_{2 \mathrm{~A}}$, and $5-\mathrm{HT}_{7}$ receptors. First, molecular docking was used to build ligand-receptor complexes of eight long-chain 
arylpiperazine ligands with three homology models of the above-mentioned serotoninergic receptors. Next, the ONIOM was used to optimize the molecular geometries of L-R complexes obtained in molecular docking study using the B3LYP(DFT):AMBER(MM) approach. The optimized complexes were then subjected to ab initio FMO-EDA calculations at the MP2/6-31G* level of theory. We recently applied a similar scheme to investigate the allosteric binding site of the other GPCR - metabotropic glutamate receptor 1 [7]. To the best of our knowledge, this is the first study that employed ONIOM and FMO to analyze the structure of the orthosteric binding site of selected GPCRs.

\section{Methods}

\section{Ligands}

The pilot series of an active to $5-\mathrm{HT}_{1 \mathrm{~A}}$ receptor, long-chain arylpiperazine derivatives (Table 1), were used for the energy characterization of $5-\mathrm{HT}_{1 \mathrm{~A}}, 5-\mathrm{HT}_{2 \mathrm{~A}}$, and $5-\mathrm{HT}_{7}$ receptors orthosteric binding site. The affinity of the compounds was evaluated in vitro by radioligand binding experiments as described previously [22]. Selected ligands belong to a very popular and widely studied class of compounds for these pharmacological targets [22-25]. The calculation scheme was as follows: molecular docking, ONIOM optimization, and single-point energy calculation with FMO-EDA method. Due to the known pharmacological profile of the lead molecule $\mathbf{1}$ it was used as a case study.

\section{Structures of the receptors}

The homology models of the selected serotonin receptors, namely $5-\mathrm{HT}_{1 \mathrm{~A}}, 5-\mathrm{HT}_{2 \mathrm{~A}}$, and $5-\mathrm{HT}_{7}$, were built on the $\mathrm{D}_{3}$ template, using the procedure described in our previous study [26, 27].

\section{Molecular docking}

The LigPrep v3.6 and Epik v3.4 were used to prepared the threedimensional structures and to assign appropriate ionization states at $\mathrm{pH}=7.4 \pm 1.0$ of the ligands, respectively. If the absolute configuration of the stereocenter was not specified, both enantiomers (R and S) were generated and used in the docking. The proteins' structures were prepared (amino acid ionization states and checking for steric clashes) by Protein Preparation Wizard. The receptors' grids were generated (OPLS3 force field) by centering the grid box with a size of $12 \AA$ on the D3.32 side chain. To determine the binding mode for all studied ligands, the ten poses for each structure were generated by using Glide v6.9 at standard precision level. All programs are part of Schrödinger Suite [28].

\section{ONIOM}

The geometries of the studied systems were fully optimized using the QM/MM:ONIOM method implemented in the Gaussian 09 [28] software. The high-level ONIOM calculations were performed for binding site, i.e., the ligand and amino acids placed a distance less than $4 \AA$ from the ligand. The $\mathrm{C}_{\mathrm{sp} 3}-\mathrm{C}_{\mathrm{sp} 3}$ bonds of amino acids were a boundary dividing the studied system, which consequently has given 254 highlevel atoms (in the case of compound $\mathbf{1}$ ). The rest of the protein was assigned to the MM fragment described by the AMBER [29] force field. The DFT method B3LYP [30, 31] in combination with split-valence basis set $6-31 G^{*}$ [32-37] was used for the optimization of the high-level region and the minima were confirmed by absence of imaginary frequency. Although the common ONIOM calculations use 6-31G*, previously studied systems contained a significantly smaller QM fragment. Here, we studied complexes which would require much higher calculation costs. Recently, a similar calculation protocol (ONIOM and next FMO) was applied by us to study metabotropic glutamate receptor 1 [7].

\section{FMO-EDA}

To study the importance and the nature of $\mathrm{L}-\mathrm{R}$ interactions, single-point FMO-EDA [2] calculations were performed for the all optimized complexes of 1-8 at the MP2/6-31G* level using the GAMESS program [38]. The FMO calculations were performed for the ligand and receptor binding site. This strategy has been applied recently to other GPCRs [7, 11, 18]. The FMO input commands were set as default. The pair interaction energies (PIE) and all contributions to total energies (electrostatic- $\mathrm{E}_{\mathrm{es}}$, dispersion- $\mathrm{E}_{\mathrm{dis}}$, charge-transfer$\mathrm{E}_{\mathrm{ct}}$, exchange repulsion- $\mathrm{E}_{\mathrm{ex}}$, and the Gibbs solvation energy $\left.-\Delta G_{\text {solv }}\right)$ were calculated as previously described [2, $4,11]$. The Gibbs solvation energy was calculated based on the PCM model. GaussView 5.0 [39] and FACIO [40] were used for preparation of the systems and analysis of the results.

In order to illustrate the nature of interactions with individual amino acid residues, the percentage share of the sum of the absolute values of electrostatic contribution and charge transfer in relation to the sum of the absolute values of the three contributions $\mathrm{E}_{\mathrm{es}}, \mathrm{E}_{\mathrm{ct}}$, and $\mathrm{E}_{\mathrm{disp}}$ was defined according to the formula:

$\% E_{e s+c t}=\frac{\left|E_{e s}\right|+\left|E_{c t}\right|}{\left|E_{e s}\right|+\left|E_{c t}\right|+\left|E_{\text {disp }}\right|} \times 100 \%$

In this way, the value is always positive and considers the different signs of contributions. The above parameter could be read in such a way that $100 \%$ means a purely polar interaction. The value $0 \%$ means simultaneously $100 \%$ of the dispersion energy, which could be interpreted as a purely hydrophobic 
Table 1 Structures of the compounds studied and their binding profile to $5-\mathrm{HT}_{1 \mathrm{~A}}, 5-\mathrm{HT}_{2 \mathrm{~A}}, 5-\mathrm{HT}_{7}$

Cmpd.

Structure

2<smiles>O=S(=O)(NCCCCCCN1CCN(c2ccccc2Cl)CC1)c1ccc2ccccc2c1</smiles>

3<smiles>O=C(NCCCCCCN1CCN(c2ccccc2Cl)CC1)c1ccccc1</smiles>

4<smiles>COc1ccccc1N1CCN(CCCCCCNS(=O)(=O)c2ccc3ccccc3c2)CC1</smiles>

5<smiles>COc1ccccc1N1CCN(CCCCCCNC(=O)c2ccccc2O)CC1</smiles>

6<smiles>COc1ccccc1N1CCN(CCCCCCOc2ccccc2C(N)=O)CC1</smiles>

7<smiles>COc1ccccc1N1CCN(CCCCCCN2C(=O)c3ccccc3C2=O)CC1</smiles>

8<smiles>COc1ccccc1N1CCN(CCCCCCn2c(=O)oc3c(c2=O)=CCCC=3)CC1</smiles>

Receptor binding $K_{\mathrm{i}}(\mathrm{nM})$

5-HT ${ }_{1 \mathrm{~A}}$

5-HT ${ }_{2 \mathrm{~A}}$

5-HT 7 Ref

9

362

248

170

426

36

23

498

260

399

53

N/A N/A

[21]

N/A

208

22

N/A

118

[23]

18

$\mathrm{N} / \mathrm{A}$

112 effect. The following example was prepared to exemplify in more detail how the approach works. For instance, ligand 2 complexed with the $5-\mathrm{HT}_{1 \mathrm{~A}}$ receptor, among others, showed interactions with I3.29 and D3.32, for which the PIE and contributions to the total energy were calculated (Table 2). Using the above-mentioned formula (2), the $\% \mathrm{E}_{\mathrm{es}+\mathrm{ct}}$ was 
Table 2 Calculated pair interaction energies (PIE; kcal $/ \mathrm{mol})$ and the contributions to the total energy $\left(\mathrm{E}_{\mathrm{es}}, \mathrm{E}_{\mathrm{ex}}, \mathrm{E}_{\mathrm{ct}+\mathrm{mix}}, \mathrm{E}_{\mathrm{dis}}, \mathrm{G}_{\mathrm{sol}} ; \mathrm{kcal} / \mathrm{mol}\right)$ between ligand 2 and two selected residues of $5-\mathrm{HT}_{1 \mathrm{~A}}$ receptor. The estimated value of $\% \mathrm{E}_{\mathrm{es}+\mathrm{ct}}$

\begin{tabular}{|c|c|c|c|c|c|c|c|}
\hline Residue of $5-\mathrm{HT}_{1 \mathrm{~A}} \mathrm{R}$ & PIE & $\mathrm{E}_{\mathrm{es}}$ & $\mathrm{E}_{\mathrm{ex}}$ & $\mathrm{E}_{\mathrm{ct}+\text { mix }}$ & $\mathrm{E}_{\text {disp }}$ & $\mathrm{G}_{\mathrm{sol}}$ & $\% \mathrm{E}_{\mathrm{es}+\mathrm{ct}}$ \\
\hline I3.29 & -11.59 & 1.39 & 5.03 & -0.92 & -5.27 & -11.81 & $30 \%$ \\
\hline D3.32 & -127.82 & -152.38 & 39.25 & -19.03 & -13.22 & 17.56 & $93 \%$ \\
\hline
\end{tabular}

estimated and illustrated in Fig. 2 later in the manuscript. The values calculated in this way suggested that the interaction with D3.32 is very strong and electrostatic in nature (characteristic for the salt bridge [41]), whereas in the case of I3.29, the main contribution was the dispersion and the interaction was medium-strong (characteristics have hydrophobic interactions). Additionally, the calculated values were consistent with hydrophobic effects estimated by Lockett et al. [42].

For PIE visualization purposes, Python scripts were prepared and executed in PyMOL v1.7.4. [43]. The notation of residues is uniform in work and means a one-letter amino acid symbol and the sequence-based generic GPCR residue number based on the scheme proposed by Ballesteros-Weinstein [44], e.g., D3.32 means aspartic acid located at position 32 in the third helix.

\section{Results and discussion}

The orthosteric binding site of serotonin receptors is well known [11, 23, 45-52] especially in the context of ligands having basic nitrogen in the structure, e.g., long-chain arylpiperazines [23, 45, 46, 49-52]. Among all serotoninergic receptors, the structure of only three has been resolved so far. Thus, homology modeling and other structure prediction methods were extensively used in the study of ligandreceptor interaction in this subfamily. However, the quality of obtained models can be affected by the template choice or/and options used in the software. Moreover, using homology modeling approach, the identification of the optimal receptor conformation for a given ligand structure is very difficult. One of the recent findings showed that this problem can be partially solved by using induced-fit docking procedure where both ligand and receptor conformations are optimized. In this study, the FMO method was used for the first time for the characterization of three non-crystallized serotonin receptors $\left(5-\mathrm{HT}_{1 \mathrm{~A}}, 5-\mathrm{HT}_{2 \mathrm{~A}}\right.$ and $\left.5-\mathrm{HT}_{7}\right)$ using a set of active ligands (Table 1).

\section{The FMO-EDA characteristics of studied serotonin receptors binding sites}

The results indicate that ligands $\mathbf{1}-\mathbf{8}$ were bound in a typical manner and showed all key contacts, such as salt bridge with D3.32 and $\pi$-stacking with F6.51/F6.52 [52].
The deeper energy picture of the binding sites of $5-\mathrm{HT}_{1 \mathrm{~A}}$, $5-\mathrm{HT}_{2, \mathrm{~A}}$ and $5-\mathrm{HT}_{7}$ receptors give the ab-initio $\mathrm{FMO}$ EDA calculations and both attracting and repulsive interactions were identified (Fig. 1). Among the non-specific interactions, there were very strong attractive one with D3.32, three stabilizing with I3.29, W6.48 and F6.51 as well as two destabilizing contacts with T3.37 and Y7.43. The results confirmed the nature of the salt bridge, and interactions with the aromatic residues of TMH6. However, the repulsive interactions were more intriguing. The first one, with the threonine 7.37 , seems to be rather specific to that group of ligands because until now it has not been mentioned as the key in any modeling studies. However, the repulsive nature of interaction with tyrosine 7.43 was unexpected. After all, this contact is observed both in $5-\mathrm{HT}_{1 \mathrm{~B}}$ and $5-\mathrm{HT}_{2 \mathrm{~B}}$ crystals [53-55] and is mentioned in many modeling studies for various serotonin receptors [11, 23, 45-51]. Considering, for example, the 5$\mathrm{HT}_{1 \mathrm{~A}}$ receptor (Table 3 ), docking studies indicated a specific $\pi-\pi$ or $\pi-\mathrm{CH}$ hydrophobic interaction $[48,56]$, while optimization of the binding site using the ONIOM method even showed the possibility to form hydrogen bonding to the ligand [22]. This phenomenon, however, can be explained in the context of the adjacent salt bridge with D3.32, which is the anchor point of the ligand, while the repulsive effect may be one of the elements of signal transduction in the receptor, i.e., the interaction causing the change in protein conformation. This argument requires more research, both theoretical and biological. Also significant was the interaction with the residue 7.36, which was stabilizing in $5-\mathrm{HT}_{1 \mathrm{~A}}$ and $5-\mathrm{HT}_{2 \mathrm{~A}}$, where the neutral (hydrophobic) alanine and polar asparagine are located, respectively. In the case of $5 \mathrm{HT}_{7}$, there is positively charged arginine and it changes from attractive to repulsive depending on the ligand. The significant PIE difference even between similar structures $\mathbf{1}$ and $\mathbf{7}$ was obtained (Table 1 and Fig. 1). However, looking at the conformations of both ligands in the binding pocket (Fig. 2), it can be seen that after ONIOM optimization the ligand 7 adopted a different arrangement of the phthalimide moiety.

The specific interactions for $5-\mathrm{HT}_{1 \mathrm{~A}}$ receptor were destabilizing with $\mathrm{I} 3.40, \mathrm{~F} 5.47$, R181 $1_{\mathrm{ECL} 2}, \mathrm{~S} 182_{\mathrm{ECL} 2}$ and attractive with residues E179 ${ }_{\mathrm{ECL} 2}$ and D180 ${ }_{\mathrm{ECL} 2}$. The most significant were the first two residues. The extracellular loops have a flexible structure and their conformations in the homology models depend on the template and modeling method. Contact with $\mathrm{I} 3.40$ occurred in five out of eight cases and it was always 

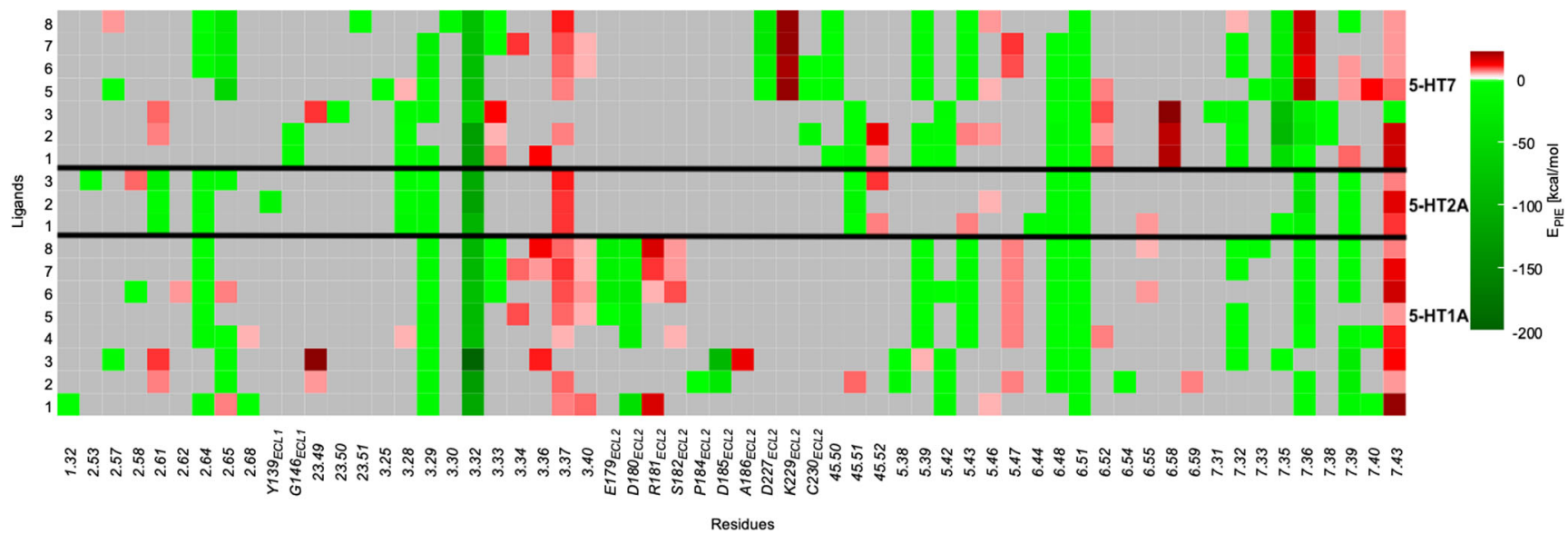

Fig. 1 Residues of serotonin receptors involved in binding of $\mathbf{1}-\mathbf{8}$. Ligand information is shown as rows, and the Ballesteros-Weinstein numbers of residues that contact the ligand are shown as columns. In is shown as a colored box, and the absence of a contact is shown as a grey box. Boxes are otherwise colored according to their $\mathrm{E}_{\mathrm{PIE}}$ : from dark green the matrix, the presence of a contact between the ligand and the residue (most attractive) to red (most repulsive)

Table 3 Comparison between $5 \mathrm{HT}_{1 \mathrm{~A}}$ binding modes determined using different computational approaches (interactions with extracellular loops were omitted)

\begin{tabular}{|c|c|c|c|c|c|c|}
\hline Residue position & Single docking ${ }^{\mathrm{a}}[24]$ & $\mathrm{QM} / \mathrm{MM}^{\mathrm{b}}[22]$ & IFD and $\mathrm{SIFt}^{\mathrm{b}}[56]$ & $\mathrm{ALiBERO}$ and $\mathrm{SIFt}^{\mathrm{c}}[48]$ & $\mathrm{MD}^{\mathrm{d}}[57]$ & $\mathrm{QM} / \mathrm{MM}$ and $\mathrm{FMO}^{\mathrm{b}}$ \\
\hline S2.54 & & & & & $X$ & \\
\hline A2.61 & & & S & $\mathrm{H}$ & & \\
\hline Y2.64 & A & & $\mathrm{FE}$ & A & & $\mathrm{a}$ \\
\hline Q2.65 & HB & & & $\mathrm{P}$ & & $\mathrm{a}$ \\
\hline F3.28 & $\mathrm{A}$ & & $\mathrm{CC}$ & A & & \\
\hline $\mathrm{I} 3.29$ & & & $\mathrm{CC}$ & & & $\mathrm{a}$ \\
\hline D3.32 & HB & HB & $\mathrm{CC}$ & HB & $\mathrm{X}$ & a \\
\hline V3.33 & $\mathrm{H}$ & $\mathrm{H}$ & $\mathrm{CC}$ & $\mathrm{H}$ & & a \\
\hline C3.36 & & & $\mathrm{CC}$ & $\mathrm{H}$ & & \\
\hline $\mathrm{T} 3.37$ & & & & & & $\mathrm{r}$ \\
\hline $\mathrm{I} 3.40$ & & & & & & $\mathrm{r}, \mathrm{S}$ \\
\hline S5.42 & & & $\mathrm{CC}$ & $\mathrm{P}$ & & $\mathrm{r}$ \\
\hline $\mathrm{T} 5.43$ & & & $\mathrm{~S}$ & $\mathrm{P}$ & & a \\
\hline A5.46 & & & & $\mathrm{H}$ & & \\
\hline F5.47 & & & S & & & $\mathrm{r}, \mathrm{S}$ \\
\hline W6.48 & & & & A & & $\mathrm{a}$ \\
\hline F6.51 & A & A & & A & $\mathrm{X}$ & $\mathrm{a}$ \\
\hline F6.52 & A & A & $\mathrm{CC}$ & A & & \\
\hline L6.58 & & $\mathrm{H}$ & & & & \\
\hline $\mathrm{T} 7.32$ & & & & & & $\mathrm{a}$ \\
\hline A7.36 & & & $\mathrm{FE}$ & $\mathrm{H}$ & & $\mathrm{a}$ \\
\hline N7.39 & HB & $\mathrm{HB}$ & $\mathrm{FE}$ & $\mathrm{P}$ & $\mathrm{X}$ & $\mathrm{a}$ \\
\hline W7.40 & HB & & S & A & & \\
\hline Y7.43 & & $\mathrm{HB}$ & S & A & & $\mathrm{r}$ \\
\hline S7.46 & & & & & $\mathrm{X}$ & \\
\hline
\end{tabular}

Homology models build on crystal structure of ${ }^{\mathrm{a}} \beta_{2} \mathrm{R},{ }^{\mathrm{b}} \mathrm{D}_{3} \mathrm{R},{ }^{\mathrm{c}} \beta_{2} \mathrm{R}$, and $5 \mathrm{HT}_{1 \mathrm{~B}} \mathrm{R}$ or ${ }^{\mathrm{d}}$ rhodopsin

Abbreviations: SIFt - Structural Interaction Fingerprints, ALiBERO - the grounded in Ligand-guided Backbone Ensemble Receptor Optimization, QM/ $\mathrm{MM}$ - the quantum mechanics/molecular mechanics hybrid method, $\mathrm{MD}$ - the molecular dynamic method; $\mathrm{CC}$ - core contact, $\mathrm{FE}$ - frequently engaged in interactions, $\mathrm{S}$ - defined the specificity of receptor, $\mathrm{H}$ - hydrophobic, $\mathrm{A}$ - aromatic, $\mathrm{P}$ - polar, $\mathrm{HB}$ - $\mathrm{H}$-bond, a - attractive, $\mathrm{r}-$ repulsive, $\mathrm{X}-$ the contact was observed over most simulation time 


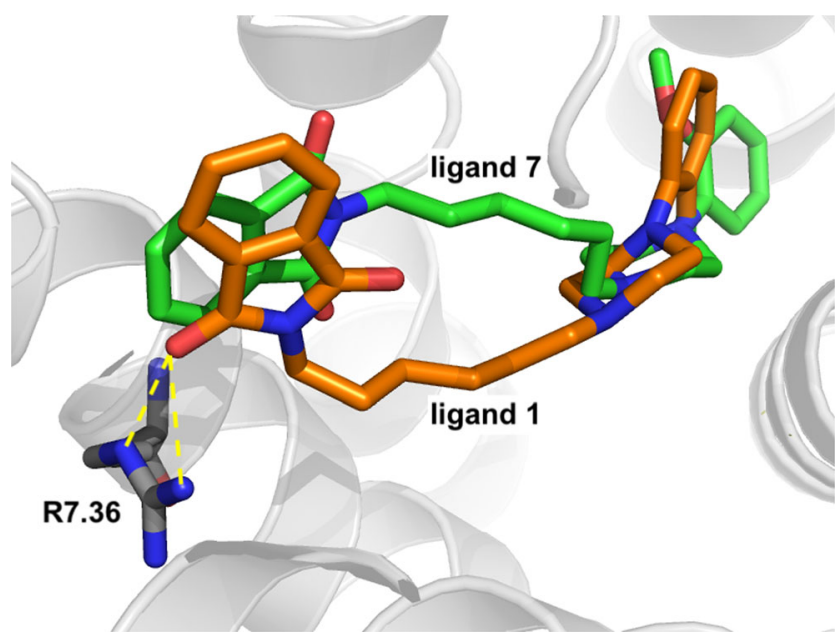

Fig. 2 ONIOM optimized complexes of ligands 1 (green) and 7 (orange) with $5-\mathrm{HT}_{7}$ receptor. Carbons of residue $\mathrm{R} 7.36$ are marked with a grey stick. The yellow dash line indicates the polar/H-bond interactions

repulsive. This very weak hydrophobic interaction involves the aromatic system of the ligand (chlorophenyl or methoxyphenyl ring) and the alkyl chain of isoleucine. The interaction with F5.47 has a similar nature. That residue is located in the same area as the previous one and also interacted with the aromatic part of the ligand. The significance of this contact is indicated by another more extensive theoretical work [56] where this interaction was classified as specific for the $5-\mathrm{HT}_{1 \mathrm{~A}}$ receptor versus the $5-\mathrm{HT}_{7}$ receptor.

For the $5-\mathrm{HT}_{7}$ receptor, results also indicated several specific interactions (Fig. 1). First, the interactions with residues D227 $\mathrm{ECL}_{2}, \mathrm{G} 230_{\mathrm{ECL} 2}, \mathrm{C} 45.50$, L45.51 and K229 ${ }_{\text {ECL2 }}$ located in the second loop should be listed, where the first four were attractive, while the last was repulsive. Moreover, the destabilizing effects from F6.52 and R6.58 and the attractive one with E7.35 were observed. This is compliant with findings of Salerno et al.
2014 [56] where the same residues were pointed as 5$\mathrm{HT}_{7}$ specific. For the $5-\mathrm{HT}_{2 \mathrm{~A}}$ receptor, there are no specific interactions.

In this work, PIEDA calculations were performed (Fig. 3) and revealed that the binding sites of the studied serotonin receptors are highly polar. The contribution of electrostatics $\left(\mathrm{E}_{\mathrm{elect}}+\mathrm{E}_{\mathrm{ct}}\right)$ in the total interaction energy (PIE) for key amino acids (I3.29, D3.32, T3.37, Y7.43) was above $70 \%$ and for W6.48 exceeded $60 \%$. Only the interaction with F6.51 can be attributed as the hydrophobic, although not fully predominant. This seems quite intuitive considering a formal positive charge of ligands, which in consequence must have an effect on the nature of the interactions.

\section{Comparison of FMO results with previous works for $5-\mathrm{HT}_{1 \mathrm{~A}}$ receptor}

Generally, in the context of previous works compiled in Table 3, the binding mode of the $5-\mathrm{HT}_{1 \mathrm{~A}}$ receptor for this group of ligands is typical. There are only three interactions not considered yet - two are repulsive, with residues of TMH3 and located at the bottom of the binding pocket (discussed above I3.40 and T3.37), and another with threonine T7.32, located at the top of the binding pocket that stabilizes the L-R complex. In addition, the FMO methodology allowed complementing or confirming the nature of interactions, postulated so far as crucial for the $5-\mathrm{HT}_{1 \mathrm{~A}}$

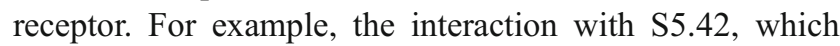
was considered as a polar and core contact $[48,56]$, caused stabilization of the L-R complex. Contact with N7.39, which was often engaged in ligand binding, being either an acceptor of hydrogen bond $[22,24]$ or forming dipoledipole interaction [48], based on the FMO calculations is a highly attractive interaction.

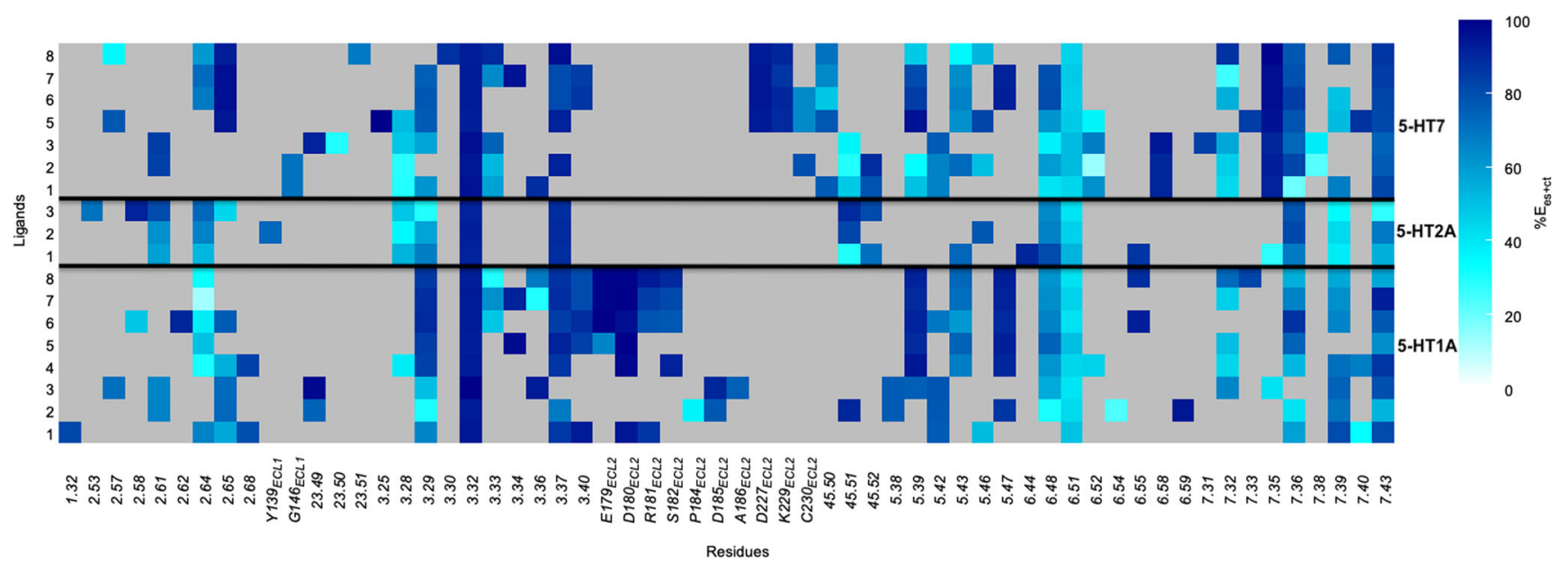

Fig. 3 Comparison of PIEDA contribution in specific ligand-receptor interactions. In the matrix, if the contact is present, boxes are colored according to their $\% \mathrm{E}_{\mathrm{es}+\mathrm{ct}}$ : from white $(0 \%$ of sum electrostatics +

charge-transfer and at the same time $100 \%$ of dispersion contributions) to dark blue ( $100 \%$ of sum electrostatics + charge-transfer). An equal contribution of the mix is light blue as shown by the right spectrum 
Fig. 4 Binding site of the serotonin receptors $\left(5-\mathrm{HT}_{1 \mathrm{~A}}, 5\right.$ $\mathrm{HT}_{2 \mathrm{~A}}$, and $5-\mathrm{HT}_{7}$ ). ONIOM optimized complexes of homology models of 5-HT receptors with ligand $\mathbf{1}$. Residues are colored according to FMO interaction energy (PIE) as shown by the spectrum below the figure. Hydrogen bonds are marked with a yellow dashed line. In the left high corner of each picture, the serotoninergic activities are shown, expressed by inhibition constant $\mathrm{K}_{\mathrm{i}}(\mathrm{nM})$

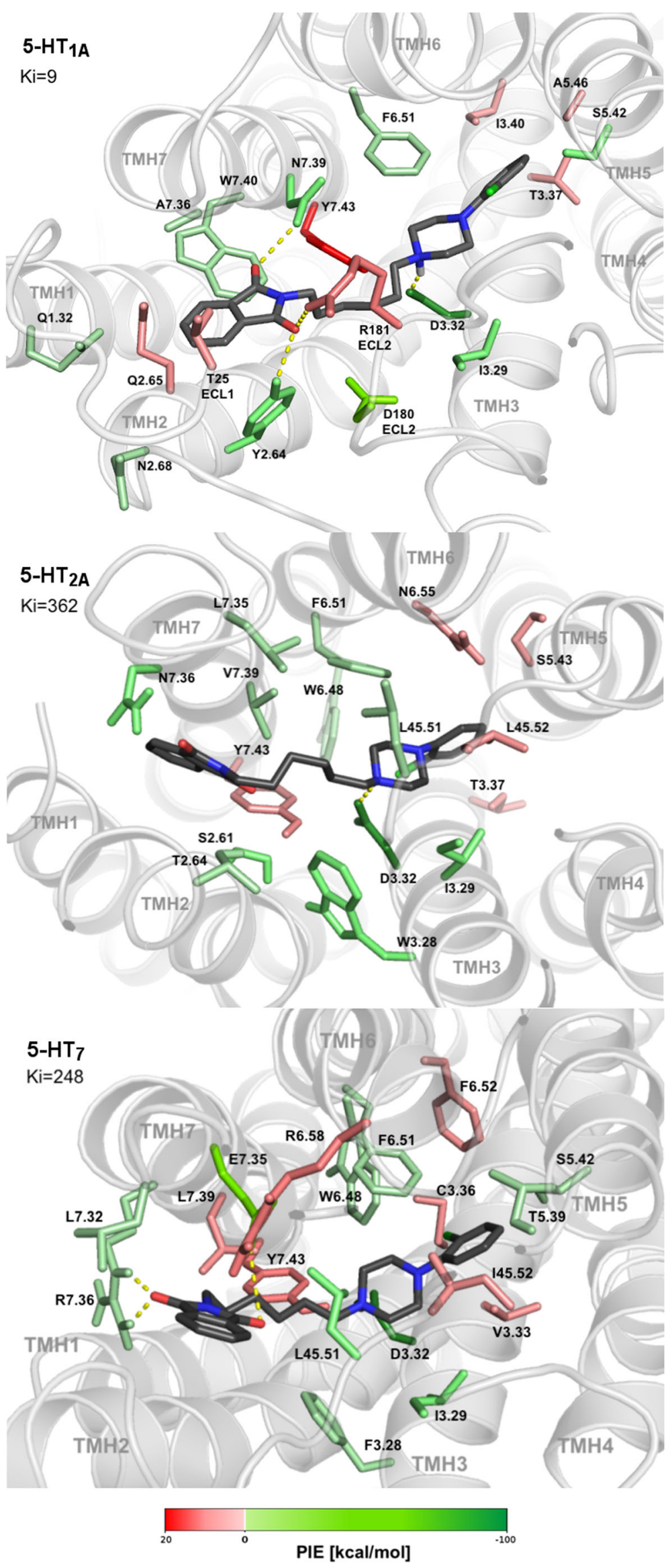




\section{Comparison between serotonin receptors - a case study for ligand 1}

For ligand $\mathbf{1}$, the in vitro activities towards the studied receptors are known (Fig. 4), however, the total energies did not correlate with the experimentally determined $\mathrm{K}_{\mathrm{i}}$ constants. Ligand $\mathbf{1}$ was bound into all receptors with comparable potency (PIE was $180.0,-169$ and $-188 \mathrm{kcal} / \mathrm{mol}$, respectively), although experimental studies showed strong activity at $5-\mathrm{HT}_{1 \mathrm{~A}}$ receptor and moderate with respect to the remaining ones. Since $\mathbf{1}$ acts as a 5$\mathrm{HT}_{1 \mathrm{~A}}$ and $5-\mathrm{HT}_{2 \mathrm{~A}}$ agonist, and $5 \mathrm{HT}_{7}$ receptor antagonist (such as aripiprazole $[45,58])$, Fig. 4 analysis allowed to hypothesize about its molecular mechanism of activation/deactivation of receptors. For the $5-\mathrm{HT}_{1 \mathrm{~A}}$ receptor, there were two repulsive areas and one large area of attraction. Abandoning interactions with residues in extracellular loops, the ligand was strongly maintained by an anchor with D3.32 and a series of interactions with residues from the upper and middle region of the binding pocket, engaging most of the helices and "keeping" them together. The destabilizing L-R complexes regions were located in the lower part of the binding pocket and could potentially be responsible for the deformation of the helix system into the proper state (active). The first, weaker and hydrophobic, involving amino acids from helices 3 and 5 (residues I3.34-I3.40, A5.46 and F5.47; Fig. 4 and Table 3). In this part, a voluminous phenyl ring of ligand 1 was placed. The second region, strongly repulsive and polar, is the last contact of $\mathbf{1}$ with helix 7, i.e., Y7.43, already mentioned above. In the case of the $5-\mathrm{HT}_{2 \mathrm{~A}}$ receptor, the arrangement is similar, with the difference that fewer amino acids are involved in repulsive interactions. For the $5-\mathrm{HT}_{7}$ receptor, there may potentially be another repulsive pocket located closer to the extracellular part of helix 6, which engages residues R6.58 and F6.52.

\section{Conclusions}

The applied approach (ONIOM/FMO-EDA) allowed us to obtain an energetic map of the binding site and facilitated the determination of the significance of individual interactions in the ligand-receptor complexes. The results showed that studied orthosteric binding sites of selected serotonin receptors have both attractive and repulsive regions. In the case of 5- $\mathrm{HT}_{1 \mathrm{~A}}$ and 5$\mathrm{HT}_{2 \mathrm{~A}}$ two repulsive areas, located in the lower part of the binding pocket, and one large area of attraction engaging many residues positioned closer to the extracellular part of the receptor were identified. Additionally, for the $5-\mathrm{HT}_{7}$ receptor, a third area of destabilization located at the extracellular end of the helix 6 was found. The correlation of these findings with the mechanism of receptor activation is currently at the center of our scientific interests and will be published in the future. Consideration of the nature of binding pocket regions in serotonin receptors could be an inspiration to design new molecules for these targets.
Acknowledgements The study was financially supported by the National Centre for Research and Development, Project LIDER VI (No. LIDER/015/L-6/14/NCBR/2015). The authors acknowledge the computing resources from PL-Grid Infrastructure. We are grateful to Prof. Andrzej J. Bojarski for research support and to Grzegorz Satała for bioassay results.

Open Access This article is distributed under the terms of the Creative Commons Attribution 4.0 International License (http:// creativecommons.org/licenses/by/4.0/), which permits unrestricted use, distribution, and reproduction in any medium, provided you give appropriate credit to the original author(s) and the source, provide a link to the Creative Commons license, and indicate if changes were made.

\section{References}

1. Fedorov DG, Kitaura K (2004) The importance of three-body terms in the fragment molecular orbital method. J Chem Phys 120:68326840

2. Fedorov DG, Kitaura K (2007) Pair interaction energy decomposition analysis. J Comput Chem 28:222-237. https://doi.org/10.1002/ jcc. 20496

3. Sekino H, Sengoku Y, Sugiki S, Kurita N (2003) Molecular orbital analysis based on fragment molecular orbital scheme. Chem Phys Lett 378:589-597. https://doi.org/10.1016/S0009-2614(03)013320

4. Fedorov DG, Kitaura K, Li H et al (2006) The polarizable continuum model (PCM) interfaced with the fragment molecular orbital method (FMO). J Comput Chem 27:976-985. https://doi.org/10. $1002 / j \mathrm{jcc} .20406$

5. Devarajan A, Markutsya S, Lamm MH et al (2013) Ab initio study of molecular interactions in cellulose I $\alpha$. J Phys Chem B 117: 10430-10443. https://doi.org/10.1021/jp406266u

6. Fedorov DG, Alexeev Y, Kitaura K (2011) Geometry optimization of the active site of a large system with the fragment molecular orbital method. J Phys Chem Lett 2:282-288. https://doi.org/10. 1021/jz1016894

7. Śliwa P, Kurczab R, Bojarski AJ (2018) ONIOM and FMO-EDA study of metabotropic glutamate receptor 1: quantum insights into the allosteric binding site. Int J Quantum Chem 118:e25617. https:// doi.org/10.1002/qua.25617

8. Watanabe C, Fukuzawa K, Tanaka S, Aida-Hyugaji S (2014) Charge clamps of lysines and hydrogen bonds play key roles in the mechanism to fix helix 12 in the agonist and antagonist positions of estrogen receptor $\alpha$ : intramolecular interactions studied by the ab initio fragment molecular orbital method. J Phys Chem B 118:4993-5008. https://doi.org/10.1021/jp411627y

9. Fletcher GD, Fedorov DG, Pruitt SR et al (2012) Large-scale MP2 calculations on the blue gene architecture using the fragment molecular orbital method. J Chem Theory Comput 8:75-79. https:// doi.org/10.1021/ct200548v

10. Hasegawa K, Noguchi T (2014) Molecular interactions of the quinone electron acceptors QA, QB, and QC in photosystem II as studied by the fragment molecular orbital method. Photosynth Res 120:113-123. https://doi.org/10.1007/s11120-012-9787-9

11. Heifetz A, Chudyk E, Gleave L et al (2016) The fragment molecular orbital method reveals new insight into the chemical nature of GPCR-ligand interactions. J Chem Inf Model 56:159-172. https:// doi.org/10.1021/acs.jcim.5b00644

12. Ishikawa T, Kuwata K (2012) RI-MP2 gradient calculation of large molecules using the fragment molecular orbital method. J Phys Chem Lett 3:375-379. https://doi.org/10.1021/jz201697x 
13. Ishikawa T, Mochizuki Y, Nakano T et al (2006) Fragment molecular orbital calculations on large-scale systems containing heavy metal atom. Chem Phys Lett 427:159-165. https://doi.org/10. 1016/j.cplett.2006.06.103

14. Kitoh-Nishioka H, Ando K (2012) Fragment molecular orbital study on electron tunneling mechanisms in bacterial photosynthetic reaction center. J Phys Chem B 116:12933-12945. https://doi.org/ $10.1021 /$ jp3062948

15. Kobayashi I, Takeda R, Suzuki R et al (2017) Specific interactions between androgen receptor and its ligand: ab initio molecular orbital calculations in water. J Mol Graph Model 75:383-389. https:// doi.org/10.1016/J.JMGM.2017.06.003

16. Morao I, Fedorov DG, Robinson R et al (2017) Rapid and accurate assessment of GPCR-ligand interactions using the fragment molecular orbital-based density-functional tight-binding method. J Comput Chem 38:1987-1990. https://doi.org/10.1002/jcc.24850

17. Amari S, Aizawa M, Zhang J et al (2006) VISCANA: visualized cluster analysis of protein-ligand interaction based on the ab initio fragment molecular orbital method for virtual ligand screening. J Chem Inf Model 46:221-230. https://doi.org/10.1021/ci050262q

18. Heifetz A, Trani G, Aldeghi M et al (2016) Fragment molecular orbital method applied to lead optimization of novel interleukin-2 inducible T-cell kinase (ITK) inhibitors. J Med Chem 59:43524363. https://doi.org/10.1021/acs.jmedchem.6b00045

19. Takeda R, Kobayashi I, Suzuki R et al (2018) Proposal of potent inhibitors for vitamin-D receptor based on ab initio fragment molecular orbital calculations. J Mol Graph Model 80:320-326. https://doi.org/10.1016/J.JMGM.2018.01.014

20. Simoncini D, Nakata H, Ogata K et al (2015) Quality assessment of predicted protein models using energies calculated by the fragment molecular orbital method. Mol Inform 34:97-104. https://doi.org/ 10.1002/minf.201400108

21. Jaśkowska J, Kowalska T, Kowalski P (2011) Cykliczne i acykliczne arylopiperazynyloalkilopochodne salicylamidu jako ligandy redceptorów serotoninowych. Postępy w Inżynierii iTechnologii Chemicznej. Wydawnictwo Politechniki Krakowskiej, Kraków, pp 79-94

22. Kowalski P, Śliwa P, Satała G et al (2017) The effect of carboxamide/sulfonamide replacement in arylpiperazinylalkyl derivatives on activity to serotonin and dopamine receptors. Arch Pharm (Weinheim) 350. https://doi.org/10.1002/ARDP.201700090

23. Kołaczkowski M, Marcinkowska M, Bucki A et al (2014) Novel arylsulfonamide derivatives with 5-HT 6 /5-HT 7 receptor antagonism targeting behavioral and psychological symptoms of dementia. J Med Chem 57:4543-4557. https://doi.org/10.1021/ jm401895u

24. Kowalski P, Jaśkowska J, Bojarski AJ et al (2011) Evaluation of 1arylpiperazine derivative of hydroxybenzamides as 5-HT1A and 5HT7 serotonin receptor ligands: an experimental and molecular modeling approach. J Heterocyclic Chem 48:192-198. https://doi. org/10.1002/jhet.526

25. Kowalski P, Mitka K, Jaśkowska J et al (2013) New arylpiperazines with flexible versus partly constrained linker as serotonin 5HT(1A)/5-HT(7) receptor ligands. Arch Pharm (Weinheim) 346: 339-348. https://doi.org/10.1002/ardp.201300011

26. Rataj K, Witek J, Mordalski S et al (2014) Impact of template choice on homology model efficiency in virtual screening. J Chem Inf Model 54:1661-1668. https://doi.org/10.1021/ci500001f

27. Kurczab R, Canale V, Satała G et al (2018) Amino acid hot spots of halogen bonding: a combined theoretical and experimental case study of the 5-HT7 receptor. J Med Chem 61:8717-8733. https:// doi.org/10.1021/acs.jmedchem.8b00828

28. Frisch MJ, Trucks GW, Schlegel HB, Scuseria GE, Robb MA, Cheeseman JR, Scalmani G, Barone V, Mennucci B, Petersson GA, Nakatsuji H, Caricato M, Li X, Hratchian HP, Izmaylov AF,
Bloino J, Zheng G, Sonnenberg JL (2009) Gaussian 09, Revision E.01

29. Cornell WD, Cieplak P, Bayly CI et al (1995) A second generation force field for the simulation of proteins, nucleic acids, and organic molecules. J Am Chem Soc 117:5179-5197. https://doi.org/10. 1021/ja00124a002

30. Becke A (1993) Density functional thermochemistry III the role of exact exchange. J Chem Phys 98:5648-5652. https://doi.org/10. $1063 / 1.464913$

31. Devlin FJ, Finley JW, Stephens PJ, Frisch MJ (1995) Ab initio calculation of vibrational absorption and circular dichroism spectra using density functional force fields: a comparison of local, nonlocal, and hybrid density functionals. J Phys Chem 99:16883-16902. https://doi.org/10.1021/j100046a014

32. Binkley JS, Pople JA, Hehre WJ (1980) Self-consistent molecularorbital methods. 21. Small split-valence basis-sets for 1st-row elements. J Am Chem Soc 102:939-947. https://doi.org/10.1021/ ja00374a017

33. Gordon MS, Binkley JS, Pople JA et al (1982) Self-consistent molecular orbital methods. 22. Small split-valence basis sets for second-row elements. J Am Chem Soc 104:2979-2803

34. Dobbs KD, Hehre WJ (1987) Molecular-orbital theory of the properties of inorganic and organometallic compounds. 6. Extended basis-sets for 2nd-row transition-metals. J Comput Chem 8:880 893

35. Dobbs KD, Hehre WJ (1986) Molecular-orbital theory of the properties of inorganic and organometallic compounds. 4. Extended basis-sets for 3rd row and 4th row, main-group elements. J Comput Chem 7:359-378

36. Dobbs KD, Hehre WJ (1987) Molecular-orbital theory of the properties of inorganic and organometallic compounds. 5. Extended basis-sets for 1st-row transition-metals. J Comput Chem 8:861-879

37. Pietro WJ, Francl MM, Hehre WJ et al (1982) Self-consistent molecular orbital methods. 24. Supplemented small split-valence basis-sets for 2nd-row elements. J Am Chem Soc 104:5039-5048

38. Schmidt MW, Baldridge KK, Boatz JA et al (1993) General atomic and molecular electronic structure system. J Comput Chem 14: 1347-1363. https://doi.org/10.1002/jcc.540141112

39. Dennington R, Keith TMJ et al (2009) GaussView, Version 5

40. Suenaga M (2014) FACIO, Version 18.8.2

41. Kurczab R, Śliwa P, Rataj K et al (2018) Salt bridge in ligandprotein complexes - systematic theoretical and statistical investigations. J Chem Inf Model 58:2224-2238. https://doi.org/10.1021/ acs.jcim. 8 b00266

42. Lockett MR, Lange H, Breiten B et al (2013) The binding of benzoarylsulfonamide ligands to human carbonic anhydrase is insensitive to formal fluorination of the ligand. Angew Chem Int Ed 52:7714-7717. https://doi.org/10.1002/anie.201301813

43. The PyMOL Molecular Graphics System, Version 1.3, Copyright $(\subset$ 2003-2010, Shrodinger LLC

44. Ballesteros JA, Weinstein H (1995) Integrated Methods for the Construction of Three-Dimensional Models and Computational Probing of Structure-Function Relations in G Protein-Coupled Receptors. Methods Neurosci 25:366-428

45. Möller D, Salama I, Kling RC et al (2015) 1,4-Disubstituted aromatic piperazines with high 5-HT2A/D2 selectivity: quantitative structure-selectivity investigations, docking, synthesis and biological evaluation. Bioorg Med Chem 23:6195-6209. https://doi.org/ 10.1016/j.bmc.2015.07.050

46. Kołaczkowski M, Nowak M, Pawłowski M, Bojarski AJ (2006) Receptor-based pharmacophores for serotonin 5-HT 7 R antagonists-implications to selectivity. J Med Chem 49:6732-6741

47. Munusamy V, Yap BK, Buckle MJC et al (2013) Structure-based identification of aporphines with selective 5-HT 2A receptorbinding activity. Chem Biol Drug Des 81:250-256. https://doi. org/10.1111/cbdd.12069 
48. Warszycki D, Rueda M, Mordalski S et al (2017) From homology models to a set of predictive binding pockets-a 5-HT1A receptor case study. J Chem Inf Model 57:311-321. https://doi.org/10.1021/ acs.jcim.6b00263

49. Bronowska A, Leś A, Chilmonczyk Z et al (2001) Molecular dynamics of buspirone analogues interacting with the 5-HT1A and 5HT2A serotonin receptors. Bioorg Med Chem 9:881-895. https:// doi.org/10.1016/S0968-0896(00)00307-2

50. Lin F, Li F, Wang C et al (2017) Mechanism exploration of arylpiperazine derivatives targeting the 5-HT2A receptor by in silico methods. Molecules 22:1064. https://doi.org/10.3390/ molecules 22071064

51. Sencanski M, Sukalovic V, Shakib K et al (2014) Molecular modeling of 5HT2A receptor-arylpiperazine ligands interactions. Chem Biol Drug Des 83:462-471. https://doi.org/10.1111/cbdd.12261

52. Vass M, Kooistra AJ, Yang D et al (2018) Chemical diversity in the G protein-coupled receptor superfamily. Trends Pharmacol Sci 39: 494-512. https://doi.org/10.1016/j.tips.2018.02.004

53. Berman HM, Westbrook J, Feng $Z$ et al (2000) The protein data bank. Nucleic Acids Res 28:235-242. https://doi.org/10.1093/nar/ 28.1.235
54. Isberg V, Mordalski S, Munk C et al (2015) GPCRdb: an information system for $\mathrm{G}$ protein-coupled receptors. Nucleic Acids Res 44: D356-D364. https://doi.org/10.1093/nar/gkv1178

55. Isberg V, Vroling B, van der Kant R et al (2014) GPCRDB: an information system for $G$ protein-coupled receptors. Nucleic Acids Res 42:D422-D425. https://doi.org/10.1093/nar/gkt1255

56. Salerno L, Pittalà V, Modica MN et al (2014) Structure-activity relationships and molecular modeling studies of novel arylpiperazinylalkyl 2-benzoxazolones and 2-benzothiazolones as 5-HT7 and 5-HT1A receptor ligands. Eur J Med Chem 85:716726. https://doi.org/10.1016/j.ejmech.2014.08.023

57. Strzelczyk AA, Jarończyk M, Chilmonczyk Z et al (2004) Intrinsic activity and comparative molecular dynamics of buspirone analogues at the 5-HT1A receptors. Biochem Pharmacol 67:22192230. https://doi.org/10.1016/j.bcp.2004.02.026

58. Ofori E, Zhu XY, Etukala JR et al (2016) Design and synthesis of dual 5-HT1Aand 5-HT7 receptor ligands. Bioorg Med Chem 24: 3464-3471. https://doi.org/10.1016/j.bmc.2016.05.053

Publisher's note Springer Nature remains neutral with regard to jurisdictional claims in published maps and institutional affiliations. 